\title{
Low-Cycle Fatigue Properties of Nickel-Based Superalloys Processed by High-Gradient Directional Solidification
}

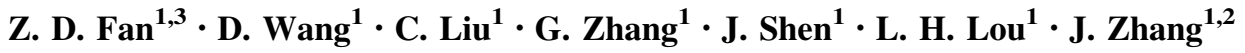

Received: 27 November 2016/Revised: 23 December 2016/Published online: 9 March 2017

(C) The Chinese Society for Metals and Springer-Verlag Berlin Heidelberg 2017

\begin{abstract}
The low-cycle fatigue (LCF) properties of DD10 (single-crystal) and DZ53 (columnar-grained) superalloys solidified by liquid-metal cooling (LMC) and high-rate solidification (HRS) processes have been systematically investigated. It was found that the LCF life of DZ53 solidified by LMC was obviously better than that solidified by HRS. In contrast, for DD10, LMC showed no remarkable influences on LCF properties at high temperature and only improved LCF properties at intermediate temperature. Microstructure examination showed that the cracks generally initiated at micropores in the subsurface at intermediate temperature. However, the cracks occurred on the surface due to oxidation, or persistent slip bands near script-MC at high temperature. Therefore, the benefits of LMC technique can be attributed to both of the reduced casting defects which significantly affect the LCF properties at intermediate temperature and the improved microstructural homogeneity which was strongly correlated to the LCF properties of alloys at high temperature.
\end{abstract}

KEY WORDS: Superalloys; Rapid solidification; Low-cycle fatigue; Microstructure

\section{Introduction}

Using high-gradient directional solidification, the superalloys for the turbine blades have been developed from conventional castings (CC) to directionally solidified (DS, columnar-grained) and single-crystal (SX) castings, where highly stressed grain boundaries were eliminated [1]. The continuous demand for an increasing turbine efficiency has pushed the alloy designers to develop superalloys

Available online at http://link.springer.com/journal/40195

D. Wang

dwang@imr.ac.cn

1 Superalloys Division, Institute of Metal Research, Chinese Academy of Sciences, Shenyang 110016, China

2 Shenyang National Laboratory for Materials Science, Institute of Metal Research, Chinese Academy of Sciences, Shenyang 110016, China

3 Xi'an Thermal Power Research Institute Co., Ltd., Xi' an 710054, China containing large amount of refractory elements and has motivated the introduction of large-size superalloy castings into industrial gas turbines (IGT) for power generation [1-4]. Such components are often physically large in dimension, particularly as compared to the corresponding aeroengine components.

When casting these high-refractory-content superalloys or large components, the industrially prevalent DS process-high-rate solidification (HRS) becomes inefficient due to low thermal gradients $[2,5]$. Severe segregation can easily occur during DS process. The segregation may lead to the formation of freckles, topological close-packed phases (TCPs) and secondary reaction zone (SRZ) $[2,5-10]$, which may significantly degrade the mechanical properties.

In order to achieve high thermal gradient at the liquidsolid interface, DS process assisted by liquid-metal cooling (LMC) is introduced for the enhancement of heat extraction $[2,11]$. It has been reported that the LMC technique not only reduced primary dendrite-arm spacing (PDAS) and casting defects, but also refined $\gamma / \gamma^{\prime}$ eutectics and 
carbides $[2,5,12-19]$. The finer the microstructure is, the shorter the solution heat treatment soak period is. It is also found that LMC can improve hot cracking resistance of DS superalloy [20].

Since the alloy mechanical property correlates strongly with the microstructure, effects of LMC technique on mechanical properties, especially on fatigue properties, have been studied. For example, Lamm et al. [15] have demonstrated that the high-cycle fatigue (HCF) strength of PWA1483 alloy at $1073 \mathrm{~K}$ can be improved by $20 \%$ for the samples by LMC comparing to those by HRS. Besides enhancing the HCF properties, it was observed that LMC technique can also increase the low-cycle fatigue (LCF) resistance of PWA1480 and René N5 SX superalloys at 811 K [17, 21]. Recently, Steuer et al. [22] also reported that the LCF life was improved up to 4 times at $1023 \mathrm{~K}$ for AM1 SX solidified by LMC in comparison with the HRS process. However, LCF properties of the LMC and HRS alloys were not distinguishable at $1223 \mathrm{~K}$.

These results reported above indicate that LMC technique is obviously beneficial to the fatigue life at room and intermediate high temperature for SX nickel-based superalloys. It seems that the improvement is mainly due to the reduction of the microporosity (both size and volume fraction) which was the origin of fatigue failure $[15,17,21,22]$. With the increase of the testing temperature, oxidation may change the crack initiation behavior, which then confined the advantages of LMC process [23]. However, there are still several open questions to be further investigated. For example, (1) no information regarding the influence of LMC on the LCF properties of superalloys has been reported at high temperature, although the data are critical for the application of the alloys; (2) the effect of LMC technique on the LCF properties of DS nickel-based superalloys is not clear. Most of previous work concentrated on SX nickel-based superalloys. Compared to SX alloys, DS superalloys have the longitudinal grain boundaries (GBs) and contain high amount of carbon and boron, which can reduce the solid solution temperature of the alloys and then make it difficult to eliminate the residual eutectic.

Therefore, the aim of our present paper is to study the LCF properties of different nickel-based superalloys processed by LMC and HRS at 1033 and $1253 \mathrm{~K}$, trying to analyze the fatigue mechanism and exploring the reasons of different fatigue behaviors.

\section{Experimental Procedures}

Two alloys, DD10 (SX nickel-based superalloy) and DZ53 (DS nickel-based superalloy) were solidified by HRS and LMC processes, respectively. The nominal compositions in weight percent (wt $\%$ ) of the two alloys are listed in
Table 1. Withdrawal rates of $3 \mathrm{~mm} / \mathrm{min}$ for DD10 and $5 \mathrm{~mm} / \mathrm{min}$ for DZ53 were applied in HRS process, while $7 \mathrm{~mm} / \mathrm{min}$ for DD10 and $12 \mathrm{~mm} / \mathrm{min}$ for DZ53 were applied in LMC process using liquid Sn as cooling medium. Estimated thermal gradients $\left(\mathrm{K} \mathrm{mm}^{-1}\right)$ were from 303 to 333 in HRS process and from 353 to 423 in LMC process. The SX and DS cylindrical bars were $16 \mathrm{~mm}$ in diameter and $220 \mathrm{~mm}$ in length. Electron backscattered diffraction (EBSD) was employed to measure the crystal orientation of the SX bars. In order to minimize the effect of elastic modulus on the fatigue performance, a maximum deviation of $8^{\circ}$ from the [001] direction was required, and the results are listed in Tables 2 and 3.

Solution and two-step aging heat treatment were performed as follows:

DD10: $1533 \mathrm{~K} / 4 \mathrm{~h} / \mathrm{AC}+1373 \mathrm{~K} / 4 \mathrm{~h} / \mathrm{AC}+1143 \mathrm{~K} / 24 \mathrm{~h} / \mathrm{AC}$.

DZ53: $1583 \mathrm{~K} / 8 \mathrm{~h} / \mathrm{AC}+1393 \mathrm{~K} / 4 \mathrm{~h} / \mathrm{AC}+1143 \mathrm{~K} / 24 \mathrm{~h} / \mathrm{AC}$.

The heat-treated bars were machined into tensile and LCF specimens. The tensile tests were carried out on an AG$250 \mathrm{KNE}$ mechanical test machine at 1033 and $1253 \mathrm{~K}$ with a constant strain rate of $1 \times 10^{-3} \mathrm{~s}^{-1}$ along the [001] direction. A servo-hydraulic testing machine was used to perform the LCF tests at 1033 and $1253 \mathrm{~K}$, with a fully reversed strain-controlled push-pull mode, i.e., $R=-1$ ( $R$ is the ratio of the minimum strain to the maximum strain for each cycle). The total axial strain was measured and

Table 1 Nominal chemical compositions of DD10 and DZ53 alloys (wt\%)

\begin{tabular}{lllllllllll}
\hline Alloy & $\mathrm{Re}$ & $\mathrm{W}$ & $\mathrm{Mo}$ & $\mathrm{Ta}$ & $\mathrm{Cr}$ & $\mathrm{Co}$ & $\mathrm{Al}$ & $\mathrm{Ti}$ & $\mathrm{C}$ & $\mathrm{Ni}$ \\
\hline $\mathrm{DD10}$ & - & 4 & 0.5 & 5 & 12 & 6 & 4 & 4 & 0.03 & Bal. \\
DZ53 & 3 & 9 & 2 & 7 & 6 & 9 & 6 & 1 & 0.1 & Bal. \\
\hline
\end{tabular}

Table 2 Fatigue properties of DD10 solidified by HRS at 1253 and $1033 \mathrm{~K}$

\begin{tabular}{lllll}
\hline $\begin{array}{l}\text { Total strain } \\
\text { range }(\%)\end{array}$ & $\begin{array}{l}\text { Fatigue } \\
\text { life } \\
1253 \mathrm{~K}\end{array}$ & $\begin{array}{l}\text { Deviation } \\
\text { from [001] }\left(^{\circ}\right)\end{array}$ & $\begin{array}{l}\text { Fatigue } \\
\text { life } \\
1033 \mathrm{~K}\end{array}$ & $\begin{array}{l}\text { Deviation } \\
\text { from [001] }\left(^{\circ}\right)\end{array}$ \\
\hline 2.4 & 114 & 3 & 20 & 5 \\
2.0 & 226 & 6 & 444 & 6 \\
1.8 & - & - & 1204 & 5 \\
1.6 & 348 & 7 & 2360 & 4 \\
1.4 & - & - & 10,344 & 6 \\
1.2 & 1144 & 6 & - & - \\
1.0 & 2174 & 7 & - & - \\
& 2964 & 5 & & \\
0.8 & 7534 & 3 & & - \\
& 5960 & 8 & & \\
\hline
\end{tabular}


Table 3 Fatigue properties of DD10 solidified by LMC at 1253 and $1033 \mathrm{~K}$

\begin{tabular}{lllll}
\hline $\begin{array}{l}\text { Total strain } \\
\text { range }(\%)\end{array}$ & $\begin{array}{l}\text { Fatigue } \\
\text { life } \\
1253 \mathrm{~K}\end{array}$ & $\begin{array}{l}\text { Deviation } \\
\text { from [001] }\left(^{\circ}\right)\end{array}$ & $\begin{array}{l}\text { Fatigue } \\
\text { life } \\
1033 \mathrm{~K}\end{array}$ & $\begin{array}{l}\text { Deviation } \\
\text { from [001] }\left(^{\circ}\right)\end{array}$ \\
\hline 2.4 & 100 & 5 & 100 & 3 \\
& 67 & 7 & & \\
2.0 & 236 & 7 & 764 & 5 \\
1.8 & - & - & 1356 & 5 \\
1.6 & 426 & 8 & 5400 & 2 \\
1.4 & 582 & 3 & 11,356 & 4 \\
1.2 & 1312 & 8 & - & - \\
& 842 & 8 & - & - \\
1.0 & 1768 & 3 & - & - \\
& 2028 & 7 & & - \\
0.8 & 5620 & 4 & - & - \\
\hline
\end{tabular}

controlled by an extensometer mounted upon the ledges of the specimens. The strain rate was $5 \times 10^{-3} \mathrm{~s}^{-1}$, applied in a triangular waveform. The temperature fluctuation over the gauge length was maintained within $\pm 2 \mathrm{~K}$.

The samples for microstructural examination were ground, polished and etched with $100 \mathrm{ml} \mathrm{H}_{2} \mathrm{O}+50 \mathrm{ml} \mathrm{HCl}+20 \mathrm{~g}$ $\mathrm{CuSO}_{4}$ (or $100 \mathrm{ml} \mathrm{H}_{2} \mathrm{O}_{2}+100 \mathrm{ml} \mathrm{HCl}$ ). The microstructural features, such as PDAS, residual eutectics, and carbides, were analyzed by optical metallography (OM) and scanning electron microscopy (SEM). At least ten micrographs per sample at a magnification of $100 \times$ were used for each measurement of PDAS and area fraction of eutectic.

Average PDAS $\left(\lambda_{1}\right)$ was measured as follows:

$\lambda_{1}=n_{\mathrm{p}}^{-1 / 2}$.

assuming a square array of dendrites where $n_{\mathrm{p}}$ was the number of primary dendrite cores per area $\left(\mu \mathrm{m}^{2}\right)$.

Area fraction of eutectic was computed by the ImagePro Plus software. X-ray computed tomography (XCT) was employed to analyze the volume fraction and maximum equivalent radius of micropores. The sample size for XCT scanning was $1 \mathrm{~mm} \times 1 \mathrm{~mm} \times 10 \mathrm{~mm}$, and all were taken from the same part of respective cylindrical bars. The fracture surfaces and representative longitudinal sections of the fatigue specimens were observed by SEM.

\section{Results}

\subsection{Microstructure Before Fatigue}

The typical heat-treated microstructures of DD10 and DZ53 alloys are shown in Fig. 1. It can be found that PDAS of both alloys produced by LMC technique was
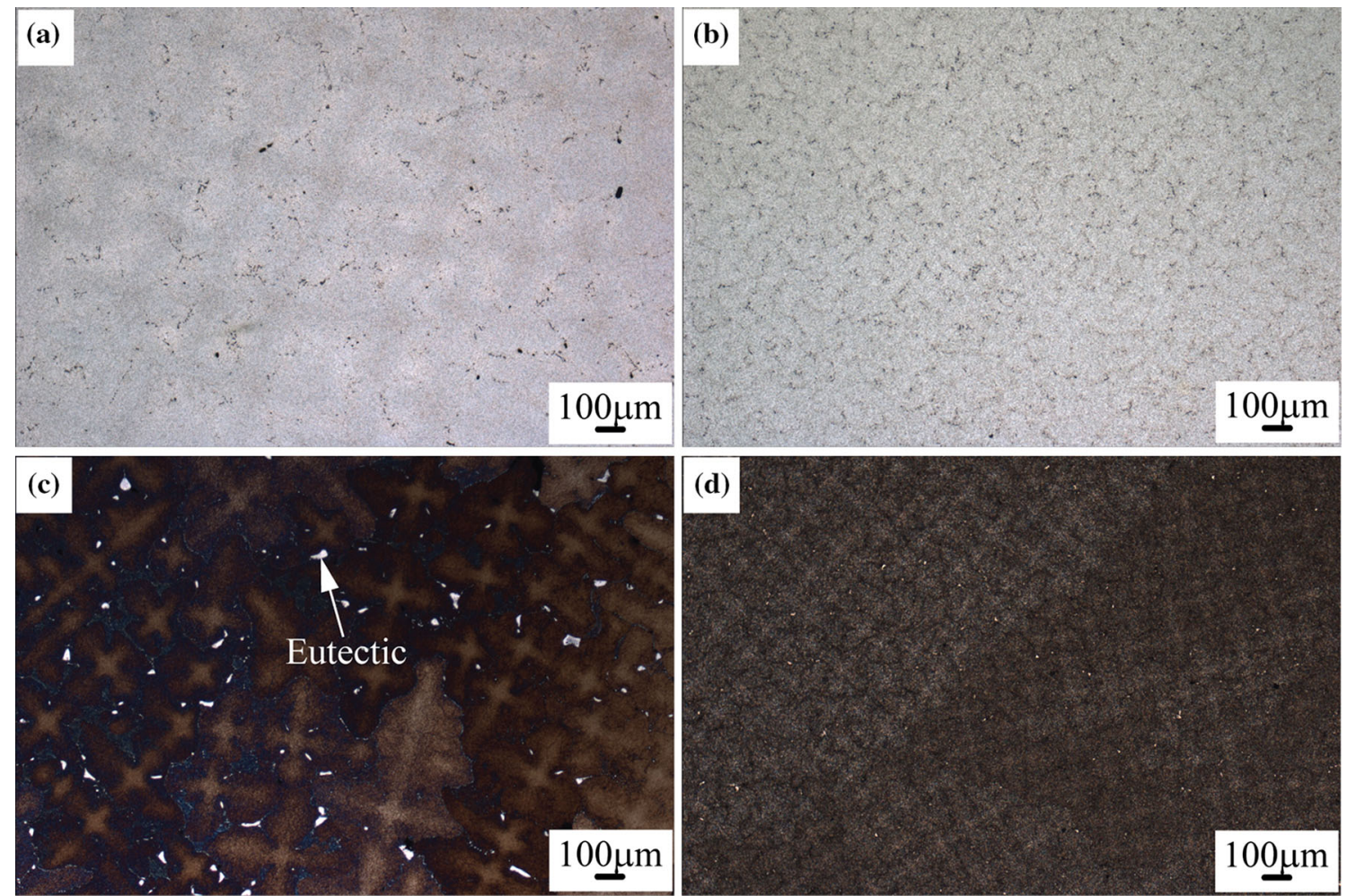

Fig. 1 OM micrographs of DD10 and DZ53 alloys after heat treatment: a DD10 alloy solidified by HRS, b DD10 alloy solidified by LMC, c DZ53 alloy solidified by HRS d DZ53 alloy solidified by LMC 

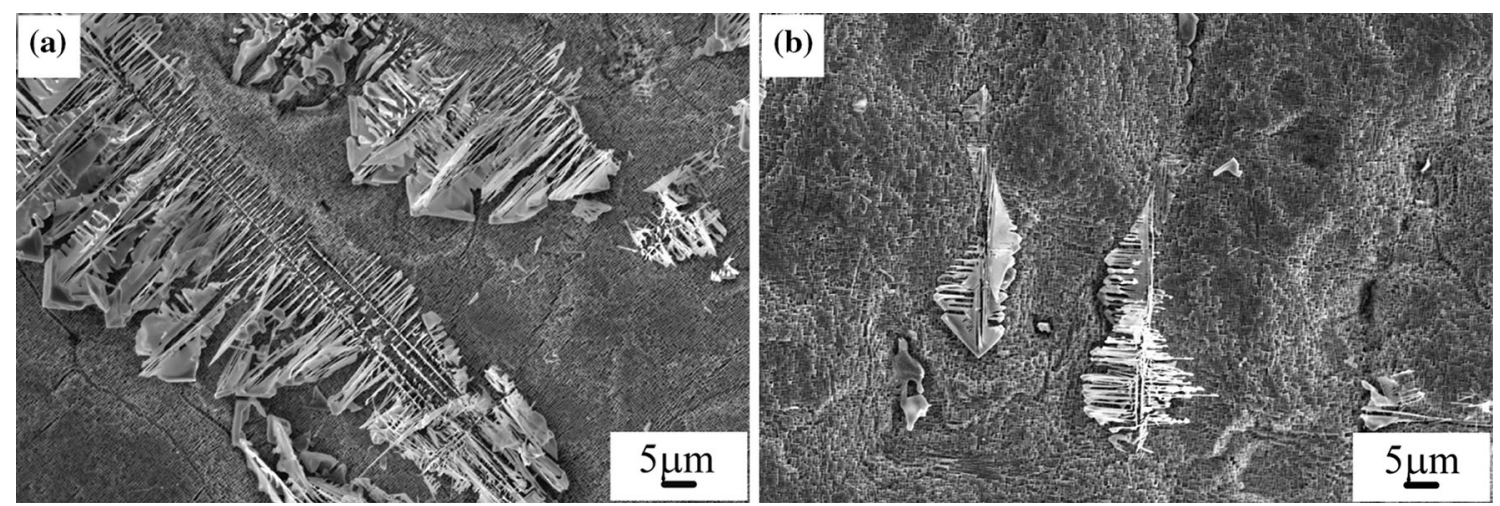

Fig. 2 Comparison of the morphologies of script carbides in DZ53: a HRS, b LMC
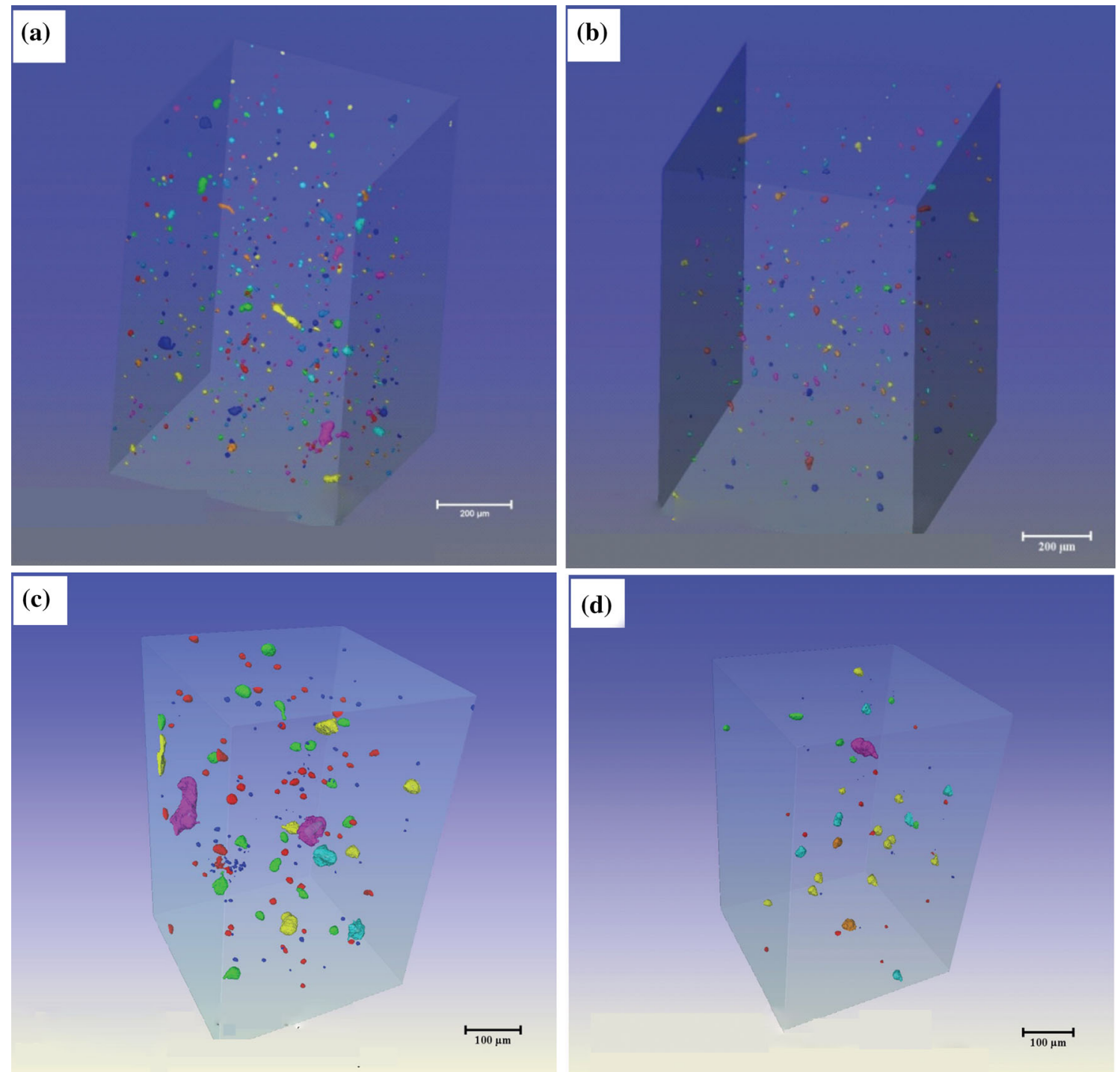

Fig. 3 Images of micropores in DD10 and DZ53 alloys after heat treatment: a DD10 alloy solidified by HRS, b DD10 alloy solidified by LMC, c DZ53 alloy solidified by HRS, d DZ53 alloy solidified by LMC 
(a)

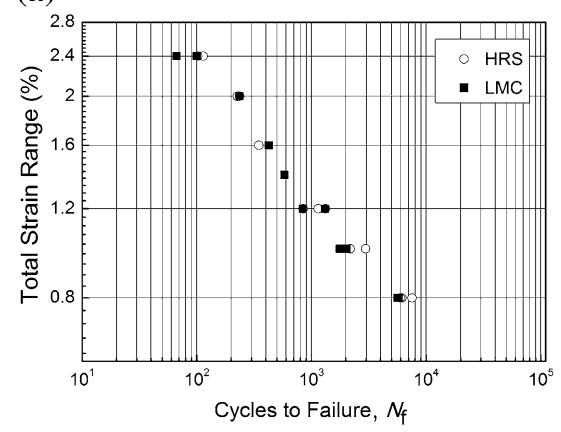

(b)

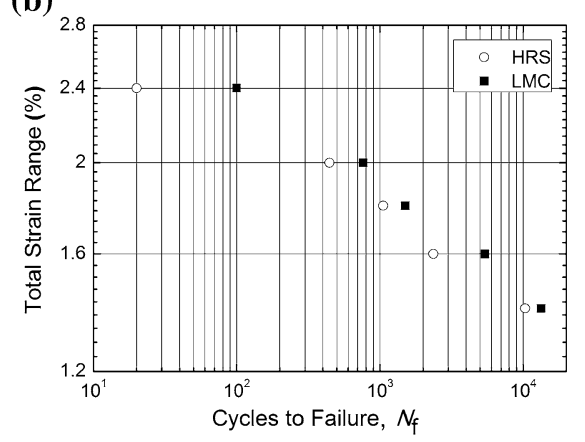

(c)

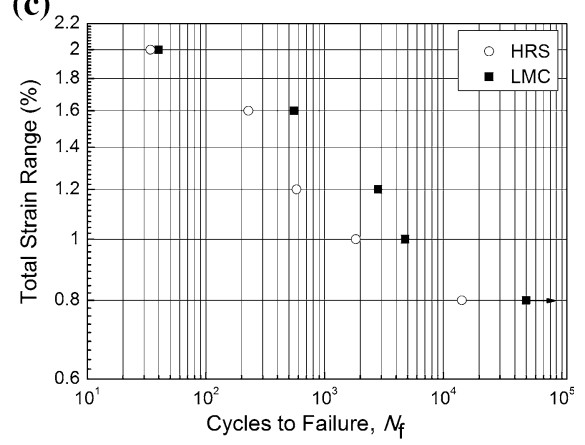

Fig. 4 LCF properties of DD10 and DZ53 alloys solidified by HRS and LMC techniques at different temperatures: a DD10 alloy at 1253 K, b DD10 alloy at $1033 \mathrm{~K}$, c DZ53 alloy at $1253 \mathrm{~K}$

Table 4 Quantitative comparison of PDAS, eutectics and microporosity

\begin{tabular}{llllll}
\hline Alloy & DS process & PDAS $(\mu \mathrm{m})$ & $\begin{array}{l}\text { Remaining } \\
\text { eutectics }(\%)\end{array}$ & $\begin{array}{l}\text { Volume fraction of } \\
\text { microporosity }(\%)\end{array}$ & $\begin{array}{l}\text { Maximum equivalent radius } \\
\text { of microporosity }(\mu \mathrm{m})\end{array}$ \\
\hline DD10 & HRS & $360 \pm 27$ & No & 0.2 & 20 \\
& LMC & $155 \pm 10$ & No & 0.08 & 15 \\
DZ53 & HRS & $345 \pm 21$ & $0.51 \pm 0.1$ & 0.45 & 28 \\
& LMC & $145 \pm 12$ & $0.02 \pm 0.006$ & 0.1 & 16 \\
\hline
\end{tabular}

significantly reduced. The overall chemical segregation is then different. After heat treatment, the microstructures of DD10 alloy solidified by HRS and LMC were comparable, containing nearly no remaining $\gamma / \gamma^{\prime}$ eutectics. However, for DZ53 alloy containing high level of refractory elements, the microstructures were significantly different. The fraction of remaining $\gamma / \gamma^{\prime}$ eutectics in HRS alloy was much higher than that of the LMC alloy. In addition, it was also found that the size of script carbides in DZ53-HRS alloy was very large (Fig. 2).

The three-dimensional (3D) features of microporosity in DD10 and DZ53 alloys solidified by LMC technique were examined by XCT, in comparison with that solidified by HRS process. Although the XCT specimen is too small to represent the whole bars, it can be seen qualitatively from Fig. 3 that the volume fraction and maximum equivalent radius of micropore were reduced by LMC technique for both alloys.

The quantitative results of the PDAS, residual $\gamma / \gamma^{\prime}$ eutectics and micropores are presented in Table 2. It can be noticed that the maximum equivalent radius of micropore in DD10 processed by HRS was decreased from $20 \mu \mathrm{m}$ to $15 \mu \mathrm{m}$ comparing with that processed by LMC. The maximum equivalent radius of micropore in DZ53 processed by HRS was decreased from 28 to $16 \mu \mathrm{m}$ comparing with that processed by LMC.

\subsection{Tensile Properties}

Results of the tensile tests are shown in Table 3. It can be seen that the yield and ultimate tensile strengths of the LMC samples are comparable to those of the HRS samples for DD10 and DZ53 alloys. However, the elongation to rupture of DZ53 alloy processed by LMC is much longer.

\subsection{LCF Properties and Fractography}

LCF results of DD10 and DZ53 alloys at different temperatures are presented in Fig. $4 \mathrm{a}-\mathrm{c}$, respectively. The total strain amplitudes are plotted as a function of the number of cycles to failure, for HRS and LMC alloys. For DD10 alloy, it was found that the casting technology showed no remarkable influences on the LCF properties at $1253 \mathrm{~K}$ and only improved the LCF properties at $1033 \mathrm{~K}$. In contrast, the $1253 \mathrm{~K} \mathrm{LCF}$ life of DZ53 solidified by LMC was obviously better than that of the alloy solidified by HRS process (Table 4).

Figure 5 shows representative SEM fractographs of DD10 alloy tested under total strain range of $1.2 \%$. At $1253 \mathrm{~K}$, the fracture surfaces (Fig. 5a, b) were covered with a thick oxide film, and the overall appearance of fracture was flat which implied that stage II mode crack propagation perpendicular to [001] was the predominant 

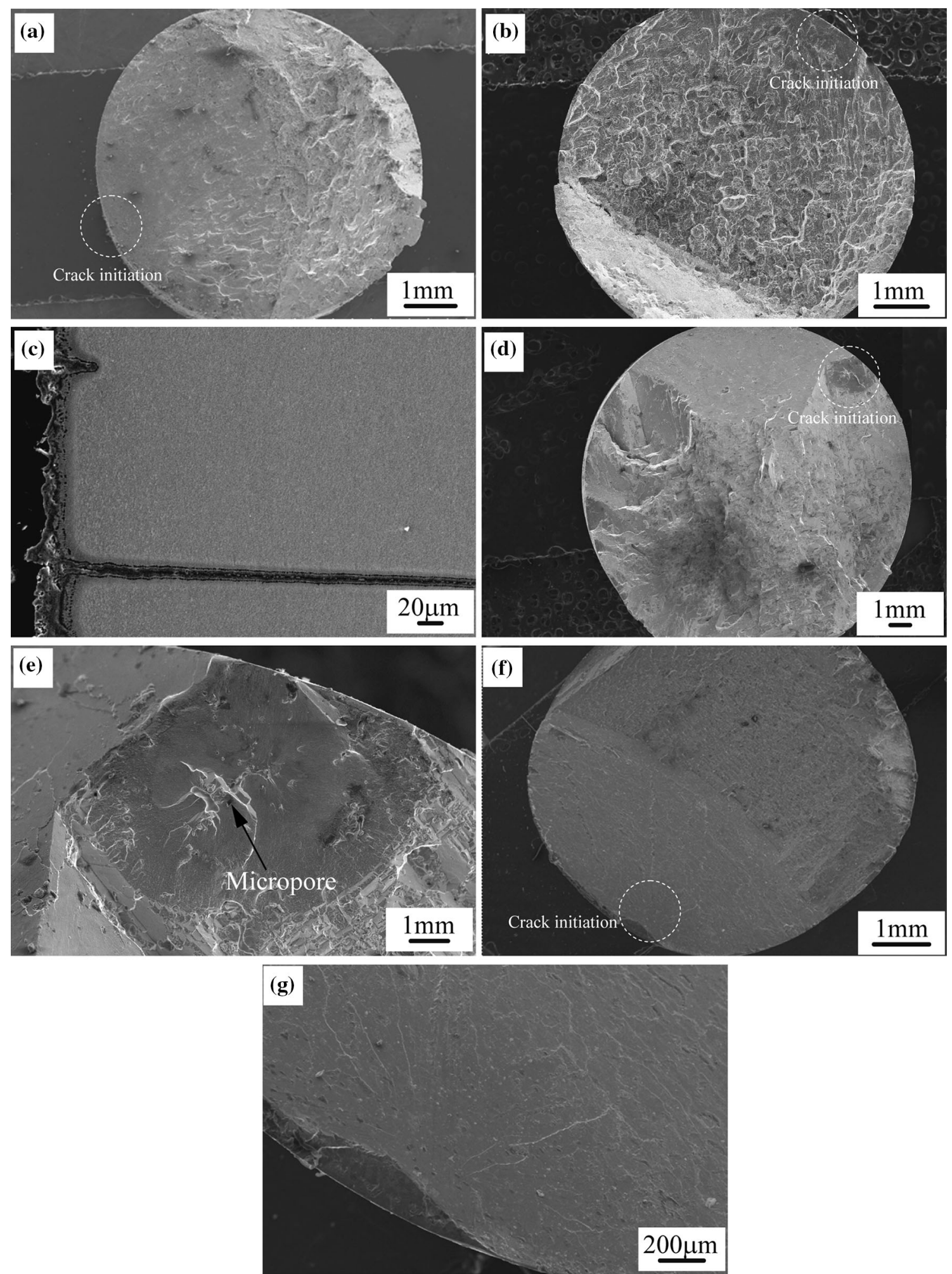

Fig. 5 LCF fractographs of DD10 alloy under total strain range of 1.2\%: a a low-magnification fractograph of HRS alloy at $1253 \mathrm{~K}$, b a lowmagnification fractograph of LMC alloy at $1253 \mathrm{~K}$, c longitudinal section microstructure of HRS alloy at $1253 \mathrm{~K}$, d a low-magnification fractograph of HRS alloy at $1033 \mathrm{~K}$, e a high-magnification fractograph of HRS alloy at $1033 \mathrm{~K}$, $\mathbf{f}$ a low-magnification fractograph of LMC alloy at $1033 \mathrm{~K}, \mathbf{g}$ a high-magnification fractograph of LMC alloy at $1033 \mathrm{~K}$ 
Table 5 Tensile properties of DD10 and DZ53 alloys solidified by HRS and LMC techniques

\begin{tabular}{|c|c|c|c|c|c|}
\hline Alloy & DS process & Temperature (K) & $0.2 \%$ YS (MPa) & UTS (MPa) & Elongation (\%) \\
\hline \multirow[t]{4}{*}{ DD10 } & HRS & 1033 & 1110 & 1330 & 13.2 \\
\hline & LMC & & 1121 & 1310 & 14.2 \\
\hline & HRS & 1253 & 392 & 636 & 24.7 \\
\hline & LMC & & 405 & 640 & 25.1 \\
\hline \multirow[t]{2}{*}{ DZ53 } & HRS & 1253 & 815 & 597 & 12.5 \\
\hline & LMC & & 844 & 613 & 23.6 \\
\hline
\end{tabular}
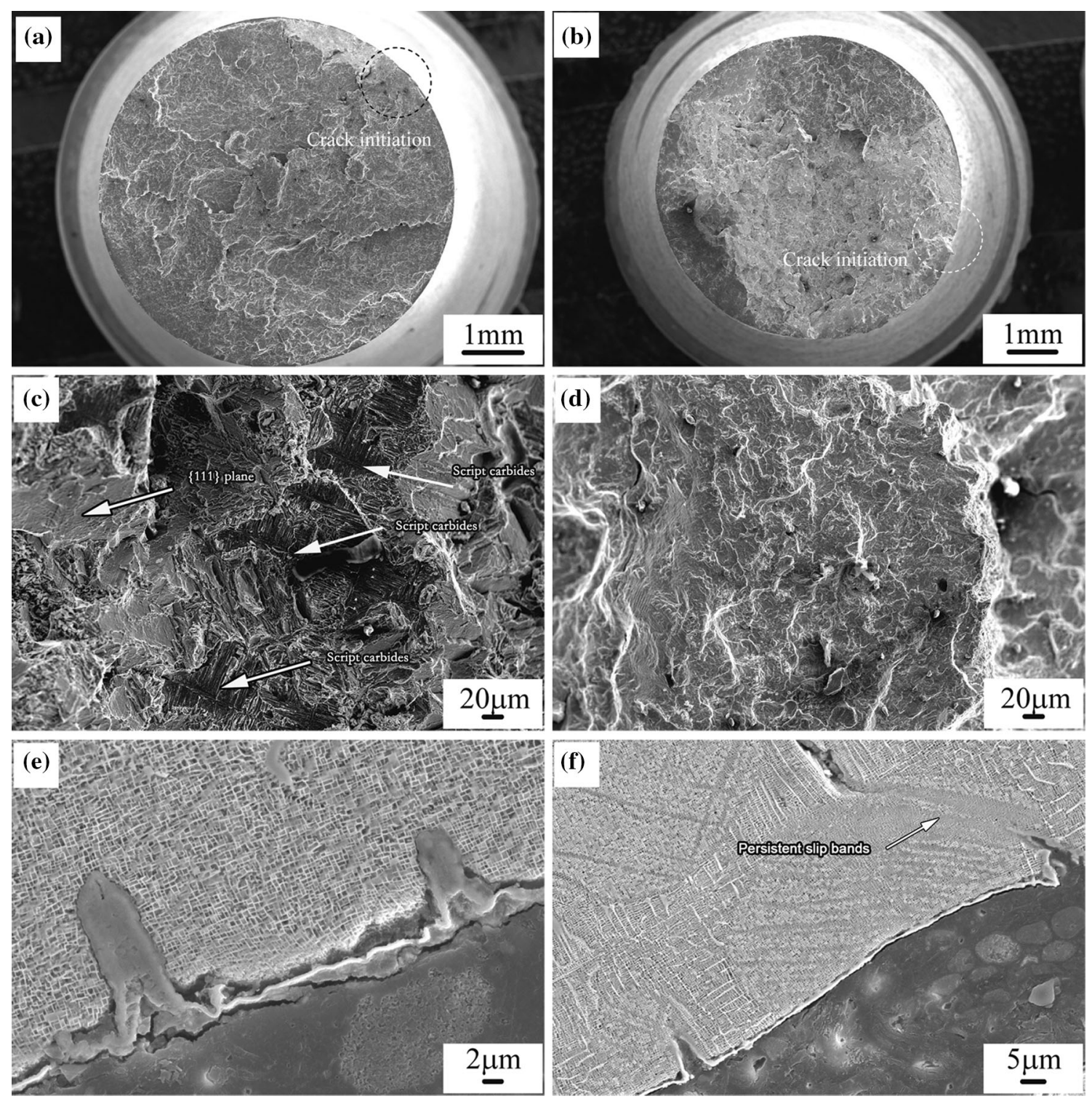

Fig. 6 LCF fractographs of DZ53 alloy under total strain range of $1.2 \%$ at $1253 \mathrm{~K}$ : a a low-magnification fractograph of HRS alloy, b a lowmagnification fractograph of LMC alloy, $\mathbf{c}$ a high-magnification fractograph of HRS alloy, $\mathbf{d}$ a high-magnification fractograph of LMC alloy, $\mathbf{e}$, f longitudinal section microstructure of HRS alloy

mode of cracking. The cracks initiated at the surfaces in both HRS and LMC specimens. However, no micropore around crack initiation region was found. Further observation of the longitudinal section (Fig. 5c) shows that the secondary cracks at the surface were induced by oxidation, i.e., breakage of the brittle oxidation layer 
accelerated the crack initiation at the surface and also promoted the penetration of the cracks (Table 5).

The fracture surface of LCF at $1033 \mathrm{~K}$ is obviously made of several $\{111\}$ planes which imply that stage I mode crack propagation on $\{111\}$ planes was predominant fracture mode (Fig. 5d, f). The crack initiation site was at subsurface for both HRS and LMC alloys. Further observation indicated that crack initiated at micropore in the HRS alloy (Fig. 5e), while no obvious defect can be found in the crack initiation region in the LMC alloy (Fig. 5f).

Figure 6 shows representative SEM fractographs of DZ53 alloy tested under total strain range of $1.2 \%$ at $1253 \mathrm{~K}$. The fracture surface of DZ53 alloy is also flat and dominated by the stage II mode perpendicular to the applied stress. Crack initiated at the surfaces in both LMC and HRS alloys, as shown in Fig. 6a and b. Under high magnification, one can also observe extensive script-MC cracking and small $\{111\}$ plane cracks in HRS alloy (Fig. 6c). For HRS alloy, one can see that both broken oxidation film (Fig. 6e) and persistent slip bands near the script-MC (Fig. 6f) could induce the initiation of cracks.

\section{Discussion}

It is known that the LCF life of the alloys depends largely on the process of crack initiation and early crack growth $[17,24]$. Considering the crack initiation process is controlled by localized cyclic plastic deformation, it can be expected that the mode of crack initiation (or the size of defects) and plasticity of alloy play important roles in the LCF life [17, 25].

At high temperature, the crack initiated at the oxidelayered surface and proceeded normal to the stress axis. For DZ53 alloy, LMC decreased significantly chemical segregation and the fraction of the remaining $\gamma / \gamma^{\prime}$ eutectics, improving oxidation resistance of alloy. In addition, the ductilities of DZ53 alloy solidified by HRS and LMC processes were apparently different, as shown in Table 3 . The low plasticity of DZ53-HRS alloy arises from the heterogeneous microstructure, which may accelerate stress concentration and promote the break of oxide layer, and therefore the crack initiation appears at the surface. In addition, the large script-MC carbides in HRS alloy can also provide a faster path for rapid propagation of fatigue cracks during LCF test. Therefore, the LCF life of DZ53 processed by HRS was obviously lower than that of the alloy obtained by LMC. Compared with DZ53 alloy, similar microstructure of DD10 alloy solidified by either HRS or LMC techniques resulted in similar oxidation resistance and nearly same plasticity. Therefore, comparable LCF properties were obtained subsequently.
At intermediate high temperature, the crack mainly initiated at the micropores near the surface and propagated predominantly along $\{111\}$ crystallographic planes, which are similar to those studied at temperatures nearby $[17,21,22]$. The effect of oxidation is not severe as it was at high temperature. The LCF life is predominantly affected by the characteristics of the defects such as the micropores in the alloys [17, 24, 25]. LMC process decreased the size and volume fraction of micropores just as observed in other superalloys [2, 15-19], which resulted in the increase of fatigue life of DD10 alloy.

It should be mentioned that we did not perform the LCF tests of DZ53 at this intermediate high temperature. However, one can infer that LMC may obviously increase LCF properties of such an alloy at $1033 \mathrm{~K}$ with relatively inhomogeneous microstructures by reducing the size and volume fraction of the micropores and residual eutectics.

\section{Conclusion}

The present work indicates that (1) at $1253 \mathrm{~K}$, the LCF life of DD10 alloy processed by HRS was almost equivalent to that of alloy processed by LMC, while the LCF life of DZ53 alloy prepared by LMC technique was superior in comparison with the DZ53 alloy solidified by HRS. At $1033 \mathrm{~K}$, the LCF life of DD10 alloy processed by LMC is comparatively longer than that of DD10 alloy prepared by HRS. (2) The benefits of LMC process can be attributed to the improved microstructural homogeneity, which was strongly correlated to the LCF properties at $1253 \mathrm{~K}$ and the reduced casting defects which significantly affected the LCF properties at $1033 \mathrm{~K}$. Such advantages were expected to be more pronounced when effect of environment is tiny or the inhomogeneity of microstructure is severer, such as in the large IGT components.

Acknowledgements This work was financially supported by the National Natural Science Foundation of China under Grant Nos. 51631008, 51101160 and 2010CB631201.

\section{References}

[1] R.C. Reed, The Superalloys Fundamentals and Applications (Cambridge University Press, Cambridge, 2006), pp. 25-32

[2] J. Zhang, L.H. Lou, J. Mater. Sci. Technol. 23, 289 (2007)

[3] B.B. Seth, Superalloys 2000 (TMS, Warrendale, PA, 2000), pp. $3-16$

[4] M.J. Goulette, Superalloys 1996 (TMS, Warrendale, PA, 1996), pp. 3-6

[5] A.F. Giamei, J.G. Tschinkel, Metall. Trans. A 7, 1427 (1976)

[6] P. Auburtin, S.L. Cockcroft, A. Mitchell, T. Wang, Superalloys 2000 (TMS, Warrendale, PA, 2000), pp. 255-261

[7] A.J. Elliott, S. Tin, W.T. King, S.C. Huang, M.F.X. Gigliotti, T.M. Pollock, Metall. Mater. Trans. A 35, 3221 (2004)

[8] S. Tin, T.M. Pollock, J. Mater. Sci. 39, 7199 (2004) 
[9] W.S. Walston, J.C. Schaeffer, W.H. Murphy, Superalloys 1996 (TMS, Warrendale, PA, 1996), pp. 9-18

[10] A. Volek, R.F. Singer, Superalloys 2004 (TMS, Warrendale, PA, 2004), pp. 713-718

[11] A.J. Elliott, T.M. Pollock, Metall. Mater. Trans. A 38, 871 (2007)

[12] A. Lohmtillert, W. Eberz, J. Grobmann, J. Preuhs, M. Hbrdler, R.F. Singer, Superalloys 2000 (TMS, Warrendale, PA, 2000), pp. $181-188$

[13] A.J. Elliott, G.B. Karney, M.F.X. Gigliotti, T.M. Pollock, Superalloys 2004 (TMS, Warrendale, PA, 2004), pp. 421-430

[14] W.G. Zhang, L. Liu, H.Z. Fu, China Found. 9, 11 (2012)

[15] M. Lamm, R.F. Singer, Metall. Mater. Trans. A 38, 1177 (2007)

[16] C.B. Liu, J. Shen, J. Zhang, J. Mater. Sci. Technol. 26, 306 (2010)
[17] C.L. Brundidge, T.M. Pollock, Superalloys 2012 (TMS, Warrendale, PA, 2012), pp. 379-385

[18] C.L. Brundidge, D. Vandrasek, B. Wang, T.M. Pollock, Metall. Mater. Trans. A 43, 965 (2012)

[19] L. Liu, T.W. Huang, M. Qu, G. Liu, J. Zhang, H.Z. Fu, J. Mater. Proc. Technol. 210, 159 (2010)

[20] C. Liu, K.W. Li, J. Shen, J. Zhang, L.H. Lou, Metall. Mater. Trans. A 43, 405 (2012)

[21] L.G. Fritzemeier, Superalloys 1988 (TMS, USA, 1988), pp. $265-274$

[22] S. Steuer, P. Villechaise, T.M. Pollock, J. Cormier, Mater. Sci. Eng. A 645, 109 (2015)

[23] T.P. Gabb, J. Gyda, Metall. Mater. Trans. A 17, 497 (1984)

[24] E. Fleury, L. Remy, Mater. Sci. Eng. A 167, 23 (1993)

[25] T. Denda, P.L. Bretz, J.K. Tien, Metall. Trans. A 23, 519 (1992) 